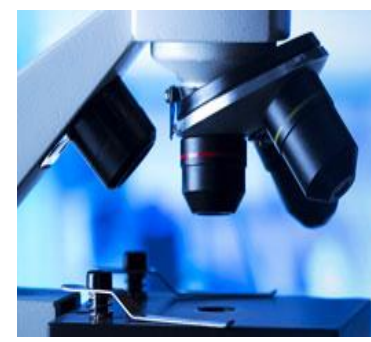

E-ISSN: 2707-4455

P-ISSN: 2707-4447

www.forensicpaper.com/

IJFM 2020; 2(1): 01-03

Received: 02-11-2019

Accepted: 05-12-2019

Dr. Jackson Dias

Department of Forensic medicine, Faculty of Medicine, University of Colombo,

Colombo, Sri Lanka
Corresponding Author: Dr. Jackson Dias

Department of Forensic medicine, Faculty of Medicine,

University of Colombo,

Colombo, Sri Lanka

\section{Assessment of gross mucosal finding in fatal stomach poisoning}

\section{Dr. Jackson Dias}

DOI: https://doi.org/10.33545/27074447.2020.v2.i1a.15

\begin{abstract}
Background: Pesticide poisoning is an important cause of morbidity and mortality in many countries in the world. The present study was conducted to assess gross mucosal stomach finding in fatal poisoning.

Materials \& methods: The present study was conducted on 54 deaths due to poisons of both genders. Stomach was dissected. Gross examination stomach was done and findings such as mucosa appearance-findings like pale, congestion, hemorrhage, erosion, flatten rugae, edema, colour changes were noted.

Results: Out of 54 patients, males were 30 and females were 24. Common poison used was Organophosphorous in 32, Sulphuric acid in 10, Hydrochloric acid in 6, Carbon monoxide in 2 and Organochlorines in 4 cases. The difference was significant $(P<0.05)$. Gross mucosal findings was paleness I 32, hemorrhage in 11, congestion in 16, erosion in 32, edema in 45 and flatten rugae in 39 cases. The difference was significant $(P<0.05)$.

Conclusion: Authors found that most common poisoning was organophosphorous followed by sulphuric acid.
\end{abstract}

Keywords: Organophosphorous, sulphuric acid, stomach

\section{Introduction}

Poison is a substance (solid, liquid, or gaseous), which if introduced in the living body, or brought into contact with any part thereof, will produce ill-health or death, by its constitutional or local effects or both. Poisoning is the commonest method adopted in India to commit suicide and $4.6 \%$ of accidental deaths were of poisoning in $2014^{[1]}$. Pesticide poisoning is an important cause of morbidity and mortality in many countries in the world. It has been estimated that $95 \%$ of fatal pesticide poisonings occur in developing countries like India.

Poisoning is the commonest method adopted in India to commit suicide. Pesticide poisoning is an important cause of morbidity and mortality in many countries in the world ${ }^{[2]}$. It has been estimated that $95 \%$ of fatal pesticide poisonings occur in developing countries, many of which are in the Asia-Pacific region. Agriculture based economies, easy availability of pesticides, poverty related socioeconomic problems, lack of adequate protective clothing, and limited treatment facilities are some of the factors contributing to the high morbidity and mortality. The incidence of insecticide poisoning has steadily increased in recent past and has reached a level where it can be called "a social calamity ${ }^{[3]}$. Due to rapid development in the field of science and technology, and vast growth in industrial and agricultural sector, poisoning is spreading like wild fire. Gross findings in stomach mucosa might be of immense help to correlate with history and treatment papers, and making the probable diagnosis of poison ${ }^{[4]}$. The present study was conducted to assess gross mucosal stomach finding in fatal poisoning.

\section{Materials \& methods}

The present study was conducted in the department of Forensic Medicine. It comprised of 54 deaths due to poisons of both genders. Ethical clearance was taken prior to the study.

General information such as name, age, gender etc. was recorded. All autopsies were done by opening of thoracic and abdominal cavity. Stomach was dissected. Gross examination stomach was done and findings such as mucosa appearance-findings like pale, congestion, hemorrhage, erosion, flatten rugae, edema, colour changes were noted. Results thus obtained were subjected to statistical analysis. $\mathrm{P}$ value less than 0.05 was considered significant. 
Results

Table 1: Distribution of patients

\begin{tabular}{|c|c|c|}
\hline \multicolumn{3}{|c|}{ Total- 54 } \\
\hline Gender & Males & Females \\
\hline Number & 30 & 24 \\
\hline
\end{tabular}

Table 1, graph 1 shows that out of 54 patients, males were 30 and females were 24 .
Table 2: Type of poison

\begin{tabular}{|c|c|c|}
\hline Poison & Number & P value \\
\hline Organophosphorous & 32 & \multirow{2}{*}{0.01} \\
\hline Sulphuric acid & 10 & \\
\hline Hydrochloric acid & 6 & \\
\hline Carbon monoxide & 2 & \\
\hline Organochlorines & 4 & \\
\hline
\end{tabular}

Table 2, graph 1 shows that common poison used was Organophosphorous in 32, Sulphuric acid in 10, Hydrochloric acid in 6, Carbon monoxide in 2 and Organochlorines in 4 cases. The difference was significant $(P<0.05)$.

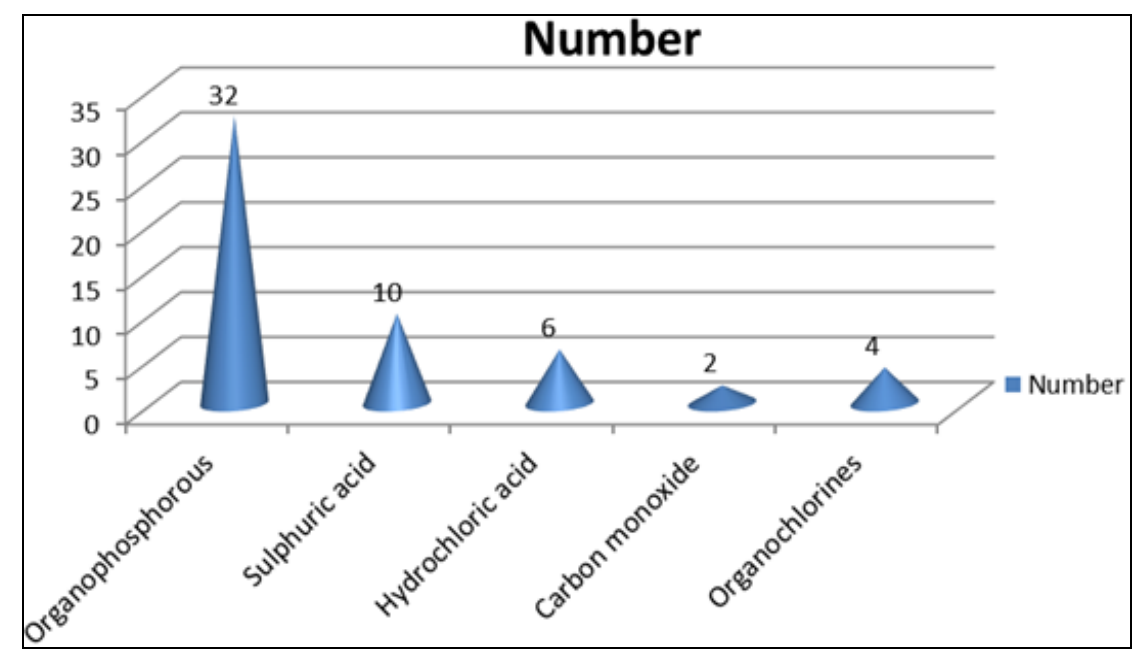

Graph 1: Type of poison

Table 3: Gross mucosal findings

\begin{tabular}{|c|c|c|}
\hline Mucosal findings & Number & P value \\
\hline Pale & 32 & \multirow{2}{*}{0.01} \\
\hline Hemorrhage & 11 & \\
\hline Congestion & 16 & \\
\hline Erosion & 32 & \\
\hline Edema & 45 & \\
\hline Flatten rugae & 39 & \\
\hline
\end{tabular}

Table 3 shows that gross mucosal findings was paleness I 32 , hemorrhage in 11 , congestion in 16 , erosion in 32 , edema in 45 and flatten rugae in 39 cases. The difference was significant $(P<0.05)$.

\section{Discussion}

Poisoning cases account for a considerable proportion of all the autopsies conducted at medico legal departments of all hospitals ${ }^{[5]}$. Diagnosis of poison in such cases depends on post mortem examination and chemical analysis of viscera at FSL. For detection of particular poison FSL have to conduct numerous tests for vast list of suspected poisons, which is time consuming activity. This delays the exact diagnosis of poison which affects the legal inquiries and increase social burdens of relatives of deceased like delay in insurance claims ${ }^{[6]}$. Due to rapid development in the field of science and technology, and vast growth in industrial and agricultural sector, poisoning is spreading like wild fire. Many authors have quoted in literature about the stomach mucosa. Colour changes in cases of poisoning, like in fatal Arsenic poisoning, the stomach mucosa has a red velvet appearance. It's leathery in Phenol (carbolic acid) poisoning and corroded $\&$ blackened in Corrosive poisonings ${ }^{[7]}$. The present study was conducted to assess gross mucosal stomach finding in fatal poisoning.

In present study, out of 54 patients, males were 30 and females were 24 . Gupta et al. ${ }^{[8]}$ in their study investigated gross mucosal findings of stomach, it was divided into three parts namely cardiac end, body-fundus and pylorus. Gross mucosal findings like pale, congestion, hemorrhage, erosion, flatten rugae, edema, colour changes were noted. Hemorrhage and congestion of mucosa were found most commonly, irrespective of type of poison and site of stomach affected. Pylorus and body fundus of stomach were more affected in all cases of poison except ALP poison where cardiac end was more affected.

We found that common poison used was Organophosphorous in 32, Sulphuric acid in 10, Hydrochloric acid in 6, Carbon monoxide in 2 and Organochlorines in 4 cases. Nigam et al. ${ }^{[9]}$ found that of total 228 fatal cases of poisoning, 159 cases $(69.7 \%)$ were males \& 69 cases $(30.3 \%)$ were females. Male: Female ratio was $2.3: 1$. The most commonly affected age group was $21-$ 30 years-70 cases $(30.7 \%)$, followed by $31-40$ years- 48 cases $(21.1 \%)$. Married were 151 cases $(66.2 \%)$ and unmarried were 76 cases $(33.3 \%)$.

We found that gross mucosal findings was paleness I 32, hemorrhage in 11 , congestion in 16 , erosion in 32 , edema in 45 and flatten rugae in 39 cases. We found that stomach was affected in all poison cases. This can be explained by that, stomach acts as reservoir in digestive tract, so contact period of poison with stomach is more. So stomach was affected more severely in all cases of poisons.

Tarunil et al. ${ }^{[10]}$ found that body and pylorus were predominately affected in most of these cases, which can be 
explained by the fact that fluid pathway from oesophagus occurs usually along lesser curvature to the pylorus. Initial exposure of the pylorus to poison causes severe spasm due to irritation, which promotes injury at this site. Stomach was uniformly affected in poisons which were not ingested by oral route like CO and snakebite. In ALP poisoning cases, cardiac and body-fundal parts of stomach were more affected, which can be explained by the fact that when ALP comes in contact with moisture phosphine gas is formed, chemical reaction is accelerated by the presence of gastric acid in stomach and gas affects the cardiac and body-fundus of stomach.

\section{Conclusion}

Authors found that most common poisoning was organophosphorous followed by sulphuric acid.

\section{References}

1. Narayan Reddy KS. The Essentials of Forensic Medicine and Toxicology. 32 ${ }^{\text {nd }}$ ed. Suguna Devi K, 2013, 473482.

2. Aggarwal P, Handa R, Wali JP. Common poisonings in India. JFMT. 1998; 15(1):73-74.

3. Kishan R, Siddpur Gurudatta S, Pawar Shashidhar C Mestri. Trends of Poisoning and Gross Stomach Mucosal Apperance in Fatal Poisoning Cases: An Autopsy Study. JIAFM. 2011; 33(2):106-111.

4. Singh B, Unnikrishnan B. A profile of acute poisoning at Mangalore (South India). Journal of Clinical Forensic Medicine. 2010; 13(3):112-116.

5. Gupta S, Kumar S, Sheikh MI. Comparative study and changing trends of poisoning in year 2004-2005, Surat, India. IJMTLM. 2007; 10(1):16-19.

6. Shetty VB, Pawar GS, Inamadar PI. Profile of poisoning cases in district and medical college hospitals of north Karnataka. IJFMT, 2008, 2(2).

7. Gupta BD, Hapani JH, Shah VN. Current trend of poisoning in Jamnagar: An experience of tertiary care teaching hospital. JIAFM. 2006; 28(3):90-92.

8. Gupta BD, Vaghela PC. Profile of fatal poisoning in and around Jamnagar. Journal of Indian Academy of Forensic Medicine. 2005; 27(3):1-5.

9. Nigam M, Jain AK, Dubey BP, Sharma VK. Trends of organophosphorus poisoning in Bhopal region-An autopsy based study. JIAFM. 2004; 26(2):62-65.

10. Tarunil NG, Bijoy TH, Momonchand A. A profile of poisoning cases admitted in RIMS hospital, Imphal. JFMT. 2001; 18(1):31-33. 